EESTI NSV TĖADUSTÉ AKADEĖMIA TOIMETISED. 29. KOIDẺ GEOLOOGIA. 1980, NR. 4

ИЗВЕСТИЯ АКАДЕМИИ НАУК ЭСТОНСКОИ ССР. ТОМ 29 ГЕОЛОГИЯ. 1980, № 4

\title{
РАСЧЛЕНЕНИЕ СРЕДНЕОРДОВИКСКИХ ОТЛОЖЕНИИ РАЗРЕЗА СКВАЖИНЫ БУТКУНАЙ (СЕВЕРО-ВОСТОК ЛИТВЫ) ПО ОСТРАКОДАМ
}

Скв. Буткунай на глубине $545,4-746,3$ м вскрыт один из наиболее полных разрезов ордовика Средне-Литовского прогиба. Среднеордовикские отложения в этом разрезе представлены стратотипической вайдленской пачкой азериского горизонта; даугавпилской свитой, охватывающей отложения ласнамягиского, ухакуского и кукрузеского горизонтов; межциемской свитой идавереского, йыхвиского, кейлаского и оандуского горизонтов; воореской свитой раквереского и набалаского горизонтов. Парастратотип даугавпилской и межциемской свит (разрез скв. Сведасай) находится 48 км юго-западнее скв. Буткунай. Воореская свита прослеживается со Средней Эстонии.

Остракоды среднеордовикского разреза скв. Буткунай собраны из 140 образцов весом около 1 кट и представлены 106 видами. Они позволяют выявить возраст целого ряда свит и пачек.

Краткая литологическая характеристика разреза дается по данным Х. Раубы (Вайтонис В. и др. Отчет о комплексных геолого-гидрогеологических съемочных работах на территории листа № 35-II в масштабе $1: 200000$, проведенных в 1969-1972 гг., Вильнюс, 1972) и Е. М. Лашкова.

Азериский горизонт $(734,5-732,4$ м) представлен красноцветными известняками вайдленской пачки рокишкской свиты. Известняки волнисто-слоистые, с ожелезненными темно-коричневыми поверхностями седиментационных перерывов. В них найден руководящий азериский вид Piretella tridactyla, встречающийся в разрезах Швеции, Юго-Восточной Әстонии, Латвии и Литвы (Jaanusson, 1957; Мянниль, 1966 и др.).

К ласнамягискому и ухакускому горизонтам относятся вижунская и краштайская пачки даугавпилской свиты. Вижунская пачка $(732,4-$ 727,6 м) сложена пестроцветными волнистослоистыми известняками с поверхностями седиментационных перерывов, а залегающая выше краштайская пачка $(727,6-721,7, м)$ - сероцветными волнисто-слоистыми известняками с единичными прослойками мергелей. Ласнамягискийухакуский возраст этих пачек определяется в первую очередь находками Steusloffia linnarssoni. Граница между этими горизонтами условно проводится на глубине 727,6 м, что в какой-то мере подтверждается находками Euprimites effusus только в вижунской пачке, a Uhakiella pumila только в краштайской. На верхней границе краштайской пачки Steusloffia linnarssoni сменяется видом Steusloffia costata, по появлению которого по всему Балтийскому бассейну фиксируется граница между ухакуским и кукрузеским горизонтами (Мянниль, 1966). 


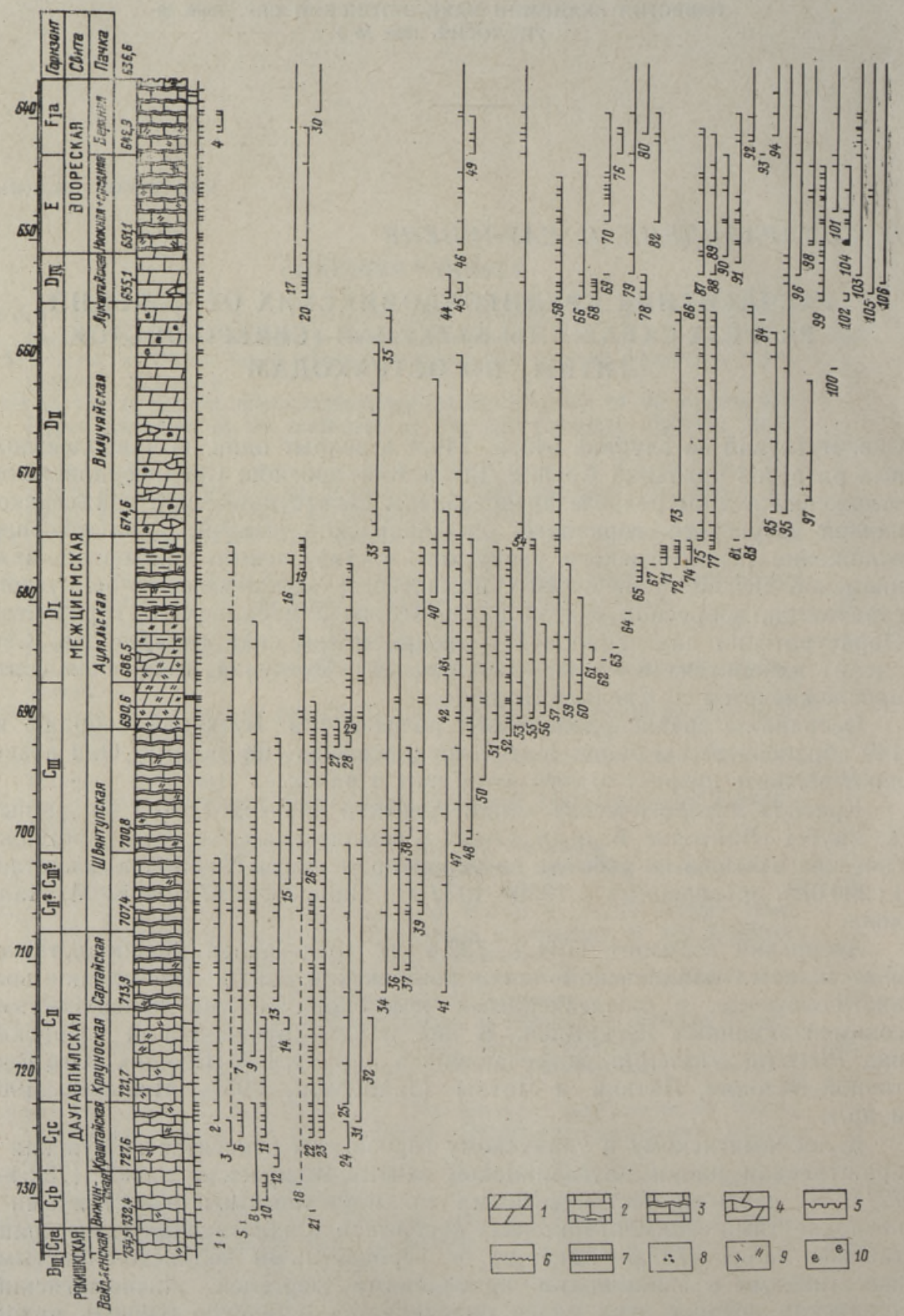

Распределение остракод в среднеордовикских отложениях разреза скв. Буткунай.

1 - Piretella tridactyla Jaanusson, $2-P$. sp. n., 3 - P. sp. sp., $4-P$. acmaea Opik, $5-$ Tallinnella sp. n., $6-T$. angustata (Krause), $7-T$. reticulata Sarv, $8-$ Steusloffia linnarssoni (Krause), $9-S$. costata (Linnarsson), $10-$ Euprimites effusus Jaanusson, $11-E$. sp., $12-E$. bursa (Krause), $13-E$. locknensis (Thorslund), $14-$ E. suecicus (Thorslund), $15-E$. sp. n., $16-$ E. bichilus Sidaraviciene, $17-$ E. kahalaensis Sarv, $18-$ Klimphores sp. sp., $19-K$. bimembris Gailite, $20-K$. 
К кукрузескому горизонту по остракодам отнесены кряуносская и сартайская пачки даугавпилской свиты. Кряуносская пачка $(721,7-$ 713,9 м), представлена сероцветными волнисто-слоистыми известняками с грубым пиритизированным детритом, а сартайская пачка $(713,9-$ 707,4 м) - сероцветными известняками с прослойками мергелей. На глубине 709,4 м отмечена прослойка (1 cm) метабентонита. Кукрузеский возраст этих пачек определяется находками вида Steusloffia costata, который сопровождается «местным» видом Uhakiella pseudopumila, известным из кукрузеских отложений других разрезов Литвы (скв. Паровея, Сведасай). В сартайской пачке, кроме того, найден вид Polyceratella bonnemai, встречающийся также в нижней части известняков Dalby в Швеции (Jaanusson, 1957). Верхняя граница кукрузеского горизонта условная.

К идаверескому и йыхвискому горизонтам отнесены швянтупская и ауляльская пачки межциемской свиты. Швянтупская пачка $(707,4-$ 690,6 м) характеризуется переслаиванием сероцветных известняков и мергелей, ауляльская $(690,6-674,0$ м) - темно-серыми волнистои горизонтально-слоистыми глинистыми известняками с прослойками темно-серого горизонтально-слоистого, неравномерно песчанистого мергеля. В нижней части пачки, где доминируют мергели, на глубинах $690,2,688,0$ и 687,7 м отмечены прослойки (1-2 cм) метабентонитов.

minimus (Sarv), 21 - Uhakiella coelodesma Öpik, $22-U$. granulifera (Ulrich et Bassler), $23-U$. kohtlensis Opik, $24-U$. pumila Opik, $25-U$. pseudopumila Sidaravičiene, $26-U$. jaanussoni Schallreuter, $27-U$. oanduensis Sarv, $28-U$. periacantha Jaanusson, $29-U$. sp. n., $30-U$. osloensis (Henningsmoen), $31-$ Perspicillum perspicillum Schallreuter, 32 - Polyceratella kuckersiana (Bonnema), 33 $P$. aluverensis Sarv, $34-P$. bonnemai Thorslund, $35-P$. spinosa Sarv, $36-$ Laccochilina decumana (Bonnema), 37 - Severella kuckersiana (Bonnema), 38 - S. severa (Sarv), $39-$ Hesslandella panis Schallreuter, $40-H$. ? auricularis (Krause), $41-$ Platybolbina sp. $1,42-P$. rima Schallreuter, $43-P$. sp. $2,44-P$. temperata Sarv, 45 - P. magna (Sarv), $46-$ P. sp. 3, 47 - Pedomphalella egregia (Sarv), $48-$ Sigmobolbina porchowiensis (Neckaja), 49 - S. sp. n., 50 - Hesperidella esthonica (Bonnema), 51 - Oecematobolbina sp., 52 - Gryphiswaldensia sp. sp., 53 - Tvaerenella sp., $54-T$. pretiosa Sarv, 55 - Bichilina prima Sarv, 56 - Henningsmoenia gunnari (Thorslund), 57 - Sigmoopsis rostrata (Krause), 58 - S. granulata (Sarv), 59 - Vittella vittensis Schallreuter, 60 - Kroemmelbeinia ala Schallreuter, 61 - Balticella binodis (Krause), 62 - Collibolbina sp., 63 - Huckea huckea Schallreuter, 64 - Neotsitrella sp., 65 - Pentagona pentagona (Jaanusson), $66-$ P. sp. п., $67-$ Pelecybolbina sp., $68-P$. illativis (Neckaja), $69-P$. pelecyoides Jaanusson, $70-$ P. composita Sidaravičiene, $71-$ Trianguloschmidtella sp., $72-$ Pyxion sp. n., $73-$ $P$. ? keilaensis Sarv, 74 - Tallinnopsis excisa (Sidaravičiene), 75 - T. iewica (Neckaja), 76 - T. sp. n., 77 - Consonopsis consona (Sarv), 78 - Tetradella zastrowensis Schallreuter, $79-T$. egorovi Neckaja, $80-T$. litwiensis Neckaja, $81-$ Bubnoffiopsis bubnoffi Schallreuter, $82-B$. incognitus Sidaravičiene, $83-$ Pseudostrepula sp. n., $84-$ P. asymmetrica Neckaja, $85-$ Conchoprimitia sp. n., 86 - Kinnekullea intermedia Gailite, 87 - Levisulculus ? rava (Sarv), 88 - Ancora parovina Sidaravičiene, $89-$ A. sp. n., 90 - Airina sp. n., 91 - Severella? sp. n., $92-$ Brevibolbina dimorpha Sarv, 93 - Primitiella ? sp. n., 94 - Distobolbina nabalaensis Sarv, 95 - Parulrichia ? tubulata Neckaja, $96-P$. inarguta Neckaja, $97-$ Bolbina sp: sp., $98-B$. sp. n., $99-B$. rakverensis Sarv, $100-$ Pseudotallinnella scopulosa Sarv, $101-$ $P$ regalis (Neckaja), $102-$ Disulcina minata Sidaravičiene, $103-D$. explicata Sarv, 104 - D. perita Sarv, 105 - Pygoconcha sp., 106 - Oepikella luminosa Sarv.

Условные обозначения к литологической колонке: 1 - мергели, $2-$ известняки горизонтально- и волнисто-слоистые, 3 - известняки волнисто-слоистые с прослойками мергелей, 4 - мергели с комками известняков, 5 - поверхность перерыва, 6 (с правой стороны колонки) поверхности седиментационных перерывов, 7 - слойки метабентонитов, 8 - глауконит, 9 - органогенно-обломочный материал, 10 - остатки фауны хорошей сохранности.

Глубины стратиграфических границ установлены по керну. По кривым карротажа они прослеживаются на $2-3 \mu$ ниже. 
Остракоды нижней части швянтупской пачки почти не отличаются от остракод сартайской пачки. Можно лишь отметить, что здесь появляется Hesslandella panis - вид, который и в других разрезах Средне-Литовского прогиба найден между основанием кукрузеского горизонта и уровнем появления идавереских Pedomphalella egregia и Bichilina prima. За пределами этого прогиба вид Hesslandella panis известен лишь по находкам из валунов (Schallreuter, 1964). Заметное обновление остракод наблюдается в средней части швянтупской пачки на глубине примерно 700 м. Здесь исчезают Tallinnella reticulata, Uhakiella pseudopumila, Piretella sp. п. (вид, близкий к Piretella tridactyla) и появляются первые редкие представители идавереских-йыхвиских остракод - Pedomphalella egregia, Sigmobolbina porchowiensis и др. Наиболее четкое изменение остракод швянтупского-ауляльского времени наблюдается в нижней более глинистой части ауляльской пачки с метабентонитами. Здесь исчезают Uhakiella jaanussoni, Uhakiella kohtlensis, Steusloffia costata, Euprimites locknensis, появляются Bichilina prima и целый ряд видов, установленных нами только в ауляльской пачке, например, Henningsmoenia gunnari, Platybolbina rima, Vittella vittensis, Balticella binodis, Huckea huckea, Oecematobolbina sp., Gryphiswaldensia sp. и др. Большинство ауляльских видов до сих пор были известны лишь по находкам из валунов, и пределы их вертикального распространения нельзя было считать окончательно установленными, однако вряд ли появление такого количества специфических видов на этом уровне является случайным. В верхней части ауляльской пачки обнаружены Euprimites bichilus, Hesslandella ? auricularis, Pentagona pentagona, первые представители рода Pelecybolbina, Tallinnopsis excisa и некоторые другие виды. В отличии от нижней части ауляльской пачки здесь не встречаются Steusloffia costata, Perspicillum perspicillum, Hesperidella esthonica, Henningsmoenia gunnari.

Таким образом, разрезы швянтупской и ауляльской пачек по составу остракод не однородны, однако наблюдаемые изменения фауны по сравнению с таковыми в отложениях идавереского и йыхвиского горизонтов Северной Эстонии (Рымусокс, 1970) не позволяют нам провести остракодовую границу этих горизонтов. Эта часть среднеордовикского разреза скв. Буткунай более достоверно сопоставляется с разрезом Fjäcka (Jaanusson, 1976), в котором нетрудно опознать уровни изменения остракод, установленные нами в нижней части и на верхней границе ауляльской пачки. Им соответствуют границы известняка Skagen. Нижняя часть ауляльской пачки, содержащая прослойки метабентонитов, сопоставляется с метабентонитовым комплексом верхов известняков Dalby. Исходя из такой корреляции границу между идавереским и йыхвиским горизонтами мы проводим на глубине 696,5 $\mathrm{M}$.

Кейлаский горизонт в разрезе скв. Буткунай выделяется в объеме вилучяйской пачки $(674,0-655,1$ м), сложенной голубовато-серыми тонко-горизонтально-слоистыми мергелями, которые в отличие от залегающих ниже пород не содержат органогенно-обломочного материала. На нижней границе пачки резко сокращается общее количество как видов, так и экземпляров остракод, исчезают Hesslandella panis, Vittella vittensis, Euprimites bichilus, Tallinnopsis excisa и др. и появ: ляются Pyxion? keilaensis, Bolbina major, Polyceratella cf. spinosa, Tallinnopsis iewica и др.

Оандуский горизонт представлен голубовато-серыми тонко-горизонтально-слоистыми мергелями с прослойками серых известняков лукштайской пачки, завершающей разрез межциемской свиты. Нижняя граница оандуского горизонта по остракодам очень резкая. Это уровень 
исчезновения Polyceratella aluverensis, Polyceratella spinosa, Pedomphalella egregia, Sigmoopsis rostrata, Pyxion? keilaensis, Tallinnopsis iewica, Consonopsis consona и появления Euprimites kahalaensis, Klimphores minimus, Platybolbina temperata, Platybolbina magna, Sigmoopsis granulata, Tetradella zastrowensis, Bolbina rakverensis, Levisulculus? rava и др. Появившаяся в лукштайской пачке фауна представлена в основном видами оандуского и раквереского горизонтов и найденными только в оандуском горизонте Kinnekullea intermedia и Pelecybolbina illativis.

Раквереский горизонт $(651,1-642,9$ м) охватывает нижнюю и среднюю части воореской свиты. Это сероцветные известняки с темными пятнами, микрозернистые и афанитовые, переслаивающиеся с голубовато-серым, тонко-горизонтально-слоистым мергелем. Здесь доминируют остракоды оандуского-раквереского возраста и появляющиеся в раквереском горизонте Bolbina sp. n., Bubnoftiopsis incognitus, Pseudotallinnella regalis. Руководящей формой раквереского горизонта в данном и других разрезах Средне-Литовского прогиба является Pelecybolbina composita.

Набалаский горизонт $(642,9-636,6$ м) охватывает верхнюю часть воореской свиты, представленную серыми и коричневато-серыми известняками с редкими прослойками темно-серого мергеля и несколькими пиритизированными поверхностями перерывов у верхней границы. В этой части воореской свиты наряду с многими видами, перешедшими из нижезалегающих слоев, появляются Distobolbina nabalaensis, Brevibolbina dimorpha, Tallinnopsis sp. n., Primitiella? sp. n., Sigmobolbina sp. n. и др. Верхняя граница набалаского горизонта по остракодам нечеткая. В практике она проводится 'по литологическим признакам по кровле воореских известняков с поверхностями перерывов, над которыми залегают мергели с прослойками известняков ревуонаской пачки мейлунской свиты (возрастные аналоги аргиллитов Fjäcka, pacпространенных западнее Средне-Литовского прогиба).

Общие черты развития среднеордовикской фауны разреза скв. Буткунай тесно связаны с фациальной характеристикой отложений. Азериская-йыхвиская фауна - это фауна трансгрессивной части разреза (красноцветные известняки вверх по разрезу сменяются сероцветными известняками с мергелями; породы органогенно-обломочные). В ней преобладают крупные, толстостенные, грубо-скульптурные формы (Uhakiella granulifera, Tallinnella reticulata, Steusloffia costata, Euprimites locknensis и др.). Вверх по разрезу, с увеличением глинистости отложений наблюдается постепенное обогащение фауны как видами, так и экземплярами. В идавереское-йыхвиское время остракоды достигают максимального видового разнообразия.

Кейлаская фауна связана с максимальной стадией ордовикской трансгрессии. В сравнительно глубоководных кейласких мергелях значительно меньше как видов, так и экземпляров остракод. Доминируют формы средних и мелких размеров - Consonopsis consona, Tallinnopsis iewica, Pyxion? keilaensis.

Оандуская-набалаская фауна - это фауна регрессивной части среднеордовикского разреза. Резкая смена фациальной обстановки вызвала резкое почти стопроцентное обновление видового состава палеокопид на границе кейлаского и оандуского горизонтов. Новая фауна характеризуется видовым разнообразием. В массовом количестве встречаются Sigmoopsis granulata, Klimphores minimus, Pelecybolbina illativis, Tetradella zastrowensis. 


\section{Л И Т Е Р А Т Р А}

М янниль Р. М. История развития Балтийского бассейна в ордовике. Таллин, 1966.

Решения Межведомственного регионального стратиграфического совещания по разработке унифицированных стратиграфических схем Прибалтики, 1976. Л., 1978.

Ры ым усокс А. Стратиграфия вируской и харьюской серий (ордовик) Северной Эстонин. I. Таллин, 1970.

Schallreuter, R. Neue Ostracoden der Oberfamilie Hollinacea. - Ber. Geol. Ges, DDR, 1964, Sonderheft 2, 87-93.

J a a nusson, V. Middle Ordovician Ostracodes of Central and Southern Sweden. Bull. Geol. Inst. Univ. Uppsala, 1957, XXXVII.

$\mathrm{J}$ a a nusson, V. Faunal dynamics in the Middle Ordovician (Viruan) of Balto-Scandia. - In: (Bassett, M. G. (ed.)) The Ordovician System: proceedings of a Palaeontological Association symposium, Birmingham, September 1974. Cardiff, 1976, 301-326.

\section{Литовский научно-исследовательский геологоразведочный институт}

Поступила в редакцию $11 / \mathrm{I} 1980$

\section{N. SIDARAVICIENE, S. SAULENIENE}

\section{BUTKUNAI (KIRDE-LEEDU) PUURAUGU LÄBILOOIKE KESKORDOVIITSIUMI SETETE LIIGESTAMINE OSTRAKOODIDE LEVIKU ALUSEL}

Butkunai puursüdamiku keskordoviitsiumi setetest on leitud 106 liiki ostrakoode. Nende leviku alusel on määratud litostratigraafiliste ühikute vanus. Esmakordselt Lōuna-Baltikumis on kindlaks tehtud erinevused idavere ja jōhvi lademe ostrakoodidefaunas ning keila lademele iseloomulikud liigid.

\section{N. SIDARAVICIENE, S. SAULENIENE}

\section{THE OSTRACODE SUBDIVISION OF MIDDLE ORDOVICIAN DEPOSITS IN THE BUTKUNAI (NORTH-EAST LITHUANIA) BORING}

The Butkunai boring, at the depth of $545.4-746.3 \mathrm{~m}$, discloses one of the most representative Ordovician sections of the Central Lithuanian depression. In the Middle Ordovician part of the profile, 106 ostracode species were detected, which allow to define the age of lithostratigraphic units - formations and members. Accordingly, the Kukruse, Idavere and Jöhvi stages in the Butkunai boring may be correlated with the Fjäcka section (Jaanusson, 1976) in Sweden. The lowermost part of the Auleliai Member is correlated with the metabentonitic complex of the uppermost Dalby Limestones, and the overlying part of that member with the Skagen Limestones. In the Butkunal boring, for the first time in the South-East Baltic, the specific features of the ostracodes belonging to the Idavere and Jõhvi stages have been defined, and the ostracode complex of the Keila Stage has been discovered in the Vilučiai Member of the Mežciems Formation. The most striking level showing changes in the composition of ostracodes has been stated at the boundary of the Keila and Oandu stages. 